\title{
Role of Wearable Sensors with Machine Learning Approaches in Gait Analysis for Parkinson's Disease Assessment: A Review
}

\author{
Aishwarya Balakrishnan, ${ }^{1}$ Jeevan Medikonda, ${ }^{1,}{ }^{*}$ Pramod Kesavan Namboothiri ${ }^{1}$ and Manikandan Natarajan ${ }^{2}$
}

\begin{abstract}
Gait analysis, a way of assessing the manner of walking, is considered a significant criterion in diagnosing movement disorder. Various factors contribute to the alterations in gait patterns, of which neurodegenerative related disorders play a major role. Subjects affected by Parkinson's disease (PD) suffer from numerous gait-related disturbances, eventually worsening their Quality of Life. Artificial intelligence-based tools have shown great interest in computer-assisted diagnosis with the recent advancements in technology. This review article aims at portraying a novel collective approach of accenting every facet of PD gait by emphasizing the role of quantitative gait analysis and state-of-art technologies in the betterment of clinical diagnosis. The paper includes all the relevant research works (2014-2021) regarding PD assessments categorized as 1) Classification of PD and Healthy subjects, 2) PD severity prediction, and 3) Freezing of Gait detection by only considering gait modality as the mode of assessment.
\end{abstract}

Keywords: Freezing of Gait; Gait Analysis; Machine Learning; Neurodegenerative disorder; Parkinson's Disease; Wearable Sensors. Received: 07 October 2021; Revised: 22 October 2021; Accepted: 12 November 2021.

Article type: Review article.

\section{Introduction}

Parkinson's disease (PD) is a chronic, persistent and long-term disorder that was first mentioned by James Parkinson in his publication "An Essay on the Shaking Palsy" in 1817. ${ }^{[1]}$ It was described as "Involuntary tremulous motion, with lessened muscular power, in parts not in action and even when supported; with a propensity to bend the trunk forward and pass from a walking to a running pace: the senses and intellects being uninjured." The remarkable clinical description of the disease, specifically motor features, was considered as a reference. Jean-Martin Charcot renamed it Parkinson's disease, which was earlier named 'Paralysis agitans.' He recognized PD in a non-tremulous form and indicated the need to differentiate slowness in the movement from lessened muscular power or weakness. A century later, in 1919 , it was recognized that brain cells, particularly in the region of substantia nigra are lost in PD subjects. Later in 1960,

\footnotetext{
${ }^{I}$ Department of Biomedical Engineering, Manipal Institute of Technology, Manipal Academy of Higher Education, Manipal, Karnataka, India.

2 Department of Physiotherapy, Manipal College of Health Professions, Manipal Academy of Higher Education, Manipal, Karnataka, India.

*Email: jeevan.m@manipal.edu (J. Medikonda)
}

the discovery that a decrease in dopamine concentration in PD patients' striatum flagged way to the initial trails of levodopa in PD patients. ${ }^{[2]}$ The development of oral levodopa in 1961 was done to validate that it can improve akinesia in patients with PD. ${ }^{[3]}$ Arvid Carlsson won Noble Prize in Medicine in the year 2000 for his contributions associated with the neurotransmitter dopamine and its effects on PD patients.

The PD is characterized by loss of dopamine-producing neurons, which manifests specific motor and non-motor symptoms such as tremors at rest, postural instability, bradykinesia, gait disturbances, rigidity/stiffness, depression, anxiety, hyposmia, and many other debilitating symptoms. ${ }^{[4]}$ From the patient's perception, PD is one of the most debilitating conditions in all chronic diseases. There are no specific diagnostic criteria, definite cure, or any proven means to prevent or slow down the disease progression. Different individuals present symptoms in varying degrees and combinations that progressively worsen over time. The heterogenic property of PD symptoms causes difficulties in accurate diagnosis, especially in the early stage due to the signs being subtle.

In recent times, the adverse impact of PD on the older generation is worsening with the increasing rate of the elderly population. About $2 \%$ of people over the age of 65 and $0.3 \%$ of the general population are affected by the so-called 
progressive neurodegenerative movement disease. ${ }^{[5]} \mathrm{PD}$ is the second most common neurodegenerative disorder, ranked after Alzheimer's disease (AD). ${ }^{[6]} \mathrm{PD}$ is not fatal, but its effect on the overall Quality of Life (QoL) of a person is indeed a matter of concern. It can affect both the economic and social aspects of human wellbeing. The economic burden is in terms of loss of employment, and medical care expenses caused due to frequent diagnoses and treatments. ${ }^{[7]}$ Social impact is instigated majorly due to the involuntary nature of symptoms (e.g., tremors in extremities, Freezing of gait (FoG) episodes, hypophonia with slurred articulation, etc.) that can lead to embarrassment as well as inhibitions caused due to the difficulties faced in performing daily-life activities.

\subsection{Epidemiology of PD}

The epidemiological studies vary among different study populations, races, and geographical locations. The root cause of PD is unknown even though complex interactions between environmental factors such as exposure to pesticides, toxic materials, age, and genetics are most likely involved. ${ }^{\left[{ }^{[3}\right.}$ Even though each element has contributions in varying proportions towards the development of the condition, age remains the most significant factor reported so far, with a male-female ratio of nearly 3:2 in most studies. ${ }^{[9]}$ The number of reported PD cases in Asian countries is slightly less than in other western countries. ${ }^{[10]}$ Considering the case of India, few studies reported the crude prevalence rate of different parts of the country. ${ }^{[11]}$ For instance, a $247 / 100,000$ prevalence rate is reported among the population over the age of 60 in the northern part of India. Similarly, a low prevalence rate of $16 / 100,000$ in rural Bengal and 27/100,000 in Bangalore is reported. The highest rate of $328 / 100,000$ is among the Parsis community living in Mumbai. Henceforward, the chances of a rise in disease prevalence rate would increase drastically in developing countries.

The onset of PD can be at any age, categorized into earlyonset, juvenile, and late-onset. Early-Onset PD (EOPD) is the onset of parkinsonian symptoms before the age of 50, which accounts for 3\%-5\% considering all PD cases. However, symptoms occurring before the age of 21 are placed into the juvenile PD category, which is often rare. Symptoms appearing in subjects within the age group of 21-40 years are known as Young-Onset PD (YOPD). ${ }^{[12]}$ Late-onset is of the age group above 60-65 years, and this group is subjected to a higher risk of developing PD. Another form of PD that represents $5 \%-10 \%$ of all cases is the genetic cause. About $10 \%-16 \%$ of PD patients have a first-order or second-order relative, of which the first-order relative may have double the risk of developing PD compared to the general population. ${ }^{[5]}$

\subsection{Cardinal symptoms of PD}

Parkinsonian symptoms usually begin gradually and worsen over time. The deterioration of motor functions manifests the progression of the disease. But the occurrence of symptoms and the rate of progression differ among individuals.
Symptoms often seem to be more severe on one side of the body than the other as the disease progresses, i.e., it is unilateral initially but eventually progresses to become bilateral by maintaining an asymmetric nature. Before experiencing stiffness, tremor, or other motor symptoms, signs of olfactory dysfunction, constipation, sleep disruptions, and restless legs are shown during the prodromal stage. The most fundamental PD features, also called cardinal symptoms, are discussed in the following sections.

\subsubsection{Resting tremor}

It is one of the most common symptoms, characterized by pillrolling or supination-pronation tremors that illustrate the rubbing of the thumb and index finger. ${ }^{[13]}$ This phenomenon represents a unilateral property with subtle rhythmic, oscillatory, involuntary movements at a frequency of $4-6 \mathrm{~Hz}$ in a fully resting limb. It vanishes with active voluntary actions and is most prominent in distal areas of extremities. Studies reported that it is one of the first signs in $69 \%$ of $\mathrm{PD}$-affected individuals, and $75 \%$ had tremors during the entire disease course. ${ }^{[14]}$ Tremors become the source of significant social anxiety and embarrassment that negatively affect an individual's self-image, sense of security, and wellbeing. Generally, it causes difficulty in writing, typing, fixing small things, dressing, eating, and every related daily-life activity that worsens with the overlapping of other symptoms. L-dopa or any antiparkinsonian medication can reduce the amplitude but not the frequency. ${ }^{[15]}$

\subsubsection{Rigidity}

Stiffness in muscles or rigidity is experienced as an increased resistance is observed during the passive movement of an affected limb. It is characterized in two ways: Cogwheel rigidity as a jerky feeling with intermittent resistance and lead pipe rigidity with resistance throughout the range of motion. ${ }^{[16]}$ Usually, it is considered the initial manifestation of PD symptoms associated with pain in joints or the shoulder, making it more prone to misdiagnosis. ${ }^{[4]}$ Postural deformities such as flexion in the neck, elbows, and knees can be caused due to stiffness in related muscles. Stooped posture while walking can be a manifestation of rigidity.

\subsubsection{Bradykinesia}

It is a clinical characteristic of PD and other related basal ganglia disorders. ${ }^{[17]}$ It refers to the slowness sensed in initiating a movement or delay in the reaction associated with it. The execution of regular daily life activities is paced down due to bradykinesia/akinesia. Other contributing symptoms of bradykinesia include dysphagia, hypomimia, hypophonia with monotonicity, reduced arm swing in gait, loss of spontaneity in handling gestures, etc.

\subsubsection{Postural instability}

It is generally observed in the later stages of the disease condition which is usually assessed by conducting a clinical 
pull test. Postural reflexes are progressively lost, leading to gait and balance impairments. ${ }^{[18]}$ Balance is compromised to prevent falling by making automatic, involuntary, and rapid adjustments, altering the person's gait. Co-occurrence with FoG leads to loss of balance and sudden falls or injuries contributing to mortality risk.

\subsection{Significance of gait analysis in PD}

Considering the symptoms that show evident manifestations even in the early disease stages, gait disturbance shows a significant ability in monitoring PD progression. ${ }^{[19]}$ Gait abnormality is one of the most evident PD symptoms that deteriorate as the disease progresses. ${ }^{[20]}$ Silvia D et al. show the potential of gait characteristics as a prodromal marker for predicting the increased risk of conversion to PD. ${ }^{[21]}$ Substantial variability in step and swing time, the measure of asymmetry in step, stance \& swing duration, cadence, and step length predicted a shorter time for PD development. Considering all the aspects, major concerns caused by gait alteration at different disease stages make it a suitable modality for disease progression analysis.

Clinical gait assessment is generally performed by human observation or patient self-reporting, where subtle changes go unnoticed without quantitative analysis. Instrumented gait assessment involves laboratory types of equipment such as Gait rites, pressure mats, etc. However, wearable sensors have exhibited promising results in monitoring every gait aspect in a real-time environment. Sensors like force plates, inertial body sensors, insole pressure sensors, and portable electromyography (EMG) support gait signals acquisition that could be further set through signal processing and analysis for disease monitoring/assessment. Table 1 lists the gait functionality aspects that are probably affected by PD and their corresponding characteristics that aid in-depth analysis of gait modality.

Artificial intelligence (AI) based tools have shown great interest in computer-assisted diagnosis. ${ }^{[22]}$ Applying AI for PD analysis can face various challenges as the symptoms are multi-faceted, and progression is heterogeneous. So, there is an immediate need to develop a more precise method that provides better diagnostic results and assists, medical practitioners, in initiating early interventions and better disease management strategies. Hence, Machine Learning (ML) based PD assessment and diagnosis is an eye-catching topic of research. Researchers have employed ML algorithms for various PD aspects with impressive results that include classifying subjects into PD and non-PD, estimating disease severity using the Unified Parkinson's Disease Rating Scale (UPDRS) scale, longitudinal cohort study, etc.

The rest of the paper is organized as mentioned. Section 2 presents the clinical analysis of PD gait followed by a quantitative analysis in Section 3. Section 4 comprises the studies conducted using the concepts of machine learning in PD gait analysis. Finally, the paper is concluded in Section 5 summarizing the limitations and directions for future research.

\section{Clinical PD gait analysis}

$\mathrm{PD}$ diagnosis is mostly subjective as there is no standard assessment protocol to confirm the disease manifestation. Diagnosis within clinical practice is made by observing various factors provided by UK Parkinson's disease society brain bank clinical diagnostic criteria. ${ }^{[23]}$ The primary diagnostic phase focuses on the presence of bradykinesia and at least any one of the symptoms such as muscle rigidity, rest tremor, or postural instability. The chance for misdiagnosis is more as the symptoms can overlap with related diseases such as essential tremor, Alzheimer's disease, etc. Thus, the next phase of diagnosis is to consider the exclusion criterion for PD as per UK Parkinson's disease society brain bank clinical diagnostic criteria. However, specific, definite PD criteria such as unilateral onset, progressive behavior of symptoms, asymmetric property, and excellent response to levodopa are closely monitored.

There are different kinds of rating scales for evaluating the impairments and disabilities faced by PD patients. Hoehn \& Yahr (H\&Y) is one of the most common for staging the disease from stage 0 (no signs $\&$ symptoms of the disease) to stage 5 (advanced to the bedridden stage). ${ }^{[24]}$ The H\&Y scale, along with the modified scaling, is represented in Table 2.

UPDRS is a similar tool for assessing the condition and gauging the course of PD in a patient. Certain modifications and revisions are done over the years by various medical groups to improve their sensitivity to detect small changes. However, UPDRS remains the basis of treatment and research in PD diagnosis. It consists of 4 major segments: Non-motor aspects of daily living experiences (nM-EDL), Motor aspects of experiences of daily living(M-EDL), Motor Examination, and Motor complications. A score of 199 represents total disability, and 0 is no disability.

According to Movement Disorder Society (MDS)UPDRS, ${ }^{[25]}$ gait is evaluated by conducting a $10 \mathrm{~m}$ (at least) straight walk starting from the examiner and then turning around to walk towards the examiner. Gait parameters such as heel strike event, arm swing, stride pace, stride time/amplitude,

Table 1. Functionality aspects of PD gait.

\begin{tabular}{|c|c|c|c|c|}
\hline Pace & Rhythm & Variability & Asymmetry & Postural control \\
\hline Step Velocity & Step time & Step time variability & Step time asymmetry & Step length asymmetry \\
\hline Step length & Swing time & Stance time variability & Swing time asymmetry & \\
\hline \multirow[t]{2}{*}{ Swing time variability } & Stance time & Step velocity variability & Stance time asymmetry & \\
\hline & & Step length variability & & \\
\hline
\end{tabular}


Table 2. Hoehn \& Yahr (H\&Y) scale to rate PD disability level.

\begin{tabular}{cll}
\hline Stages & \multicolumn{1}{c}{ H\&Y } & \multicolumn{1}{c}{ Modified H\&Y } \\
\hline 0 & - & No signs of disease \\
1 & Unilateral involvement only usually with minimal or no functional disability & Unilateral disease \\
1.5 & - & Unilateral plus axial movement \\
2 & Bilateral or midline involvement, without impairment of balance & Bilateral disease, without balance impairment \\
2.5 & - & Mild bilateral with recovery on pull test \\
3 & Mild to moderate bilateral disease; some postural instability; physically & Mild to moderate bilateral disease; some postural \\
& independent & instability; physically independent \\
4 & Severe disability; still able to walk or stand unassisted & Severe disability; still able to walk or stand unassisted \\
5 & Wheelchair-bound or bedridden unless aided & Wheelchair-bound or bedridden unless aided \\
\hline
\end{tabular}

Table 3. Gait rating scale in motor examination (MDS-UPDRS) [Copyright 2008 International Parkinson and Movement Disorder Society (MDS). All Rights Reserved. Reproduced with permission of the copyright owner. Further reproduction prohibited without permission].

\begin{tabular}{lll}
$\begin{array}{l}\text { Scor } \\
\mathrm{e}\end{array}$ & Category & Description \\
\hline 0 & Normal & $\begin{array}{l}\text { No impairments } \\
1\end{array}$ \\
Slight & $\begin{array}{l}\text { Independent walking with minor gait } \\
\text { impairment }\end{array}$ \\
2 & Mild & $\begin{array}{l}\text { Independent walking but with substantial gait } \\
\text { impairment }\end{array}$ \\
3 & Moderate & $\begin{array}{l}\text { Requires an assistance device for safe walking } \\
\text { (walking stick, walker) but not a person } \\
\text { Cannot walk at all or only with another person's } \\
\text { assistance }\end{array}$ \\
\hline
\end{tabular}

Table 4. Posture Rating Scale in Motor Examination (MDSUPDRS) [Copyright 2008 International Parkinson and Movement Disorder Society (MDS). All Rights Reserved. Reproduced with permission of the copyright owner. Further reproduction prohibited without permission].

\begin{tabular}{|c|c|c|}
\hline $\begin{array}{l}\text { Scor } \\
\text { e }\end{array}$ & Category & Description \\
\hline 0 & Normal & No problems \\
\hline 1 & Slight & $\begin{array}{l}\text { Not quite erect, but posture could be normal for } \\
\text { an older person }\end{array}$ \\
\hline 2 & Mild & $\begin{array}{l}\text { Definite flexion, scoliosis, or leaning to one } \\
\text { side, but the patient can correct posture to } \\
\text { normal posture when asked to do so. }\end{array}$ \\
\hline 3 & Moderate & $\begin{array}{l}\text { Stooped posture, scoliosis, or leaning to one } \\
\text { side cannot be corrected volitionally to a normal } \\
\text { posture by the patient. }\end{array}$ \\
\hline 4 & Severe & $\begin{array}{l}\text { Flexion, scoliosis, or leaning with an extreme } \\
\text { abnormality of posture. }\end{array}$ \\
\hline
\end{tabular}

turn characteristics, and foot lift dimensions are observed. A rating of $0-4$ is assigned to each subject and is categorized as detailed in Table 3 .

The posture while walking is evaluated to detect flexion and side-to-side bending or leaning. Similarly, FoG is also assessed while assessing gait, which is characterized by hesitation, and stuttering at the start, turn, and end of the walking task. Table $4 \&$ Table 5 represents the rating scales of posture and FoG, respectively. They are considered to determine the Postural Instability and Gait Difficulty (PIGD) score that aids in distinguishing it from the Tremor Dominant (TD) form of PD.

Table 5. Freezing of gait rating scale in motor examination (MDS-UPDRS) [Copyright 2008 International Parkinson and Movement Disorder Society (MDS). All Rights Reserved. Reproduced with permission of the copyright owner. Further reproduction prohibited without permission].

\begin{tabular}{|c|c|c|}
\hline $\begin{array}{c}\text { Scor } \\
\mathrm{e}\end{array}$ & Category & Description \\
\hline 0 & Normal & No freezing \\
\hline 1 & Slight & $\begin{array}{l}\text { Freezes on starting, turning, or walking through } \\
\text { a doorway with a single halt during any of these } \\
\text { events, but continues smoothly without freezing } \\
\text { during straight walking }\end{array}$ \\
\hline 2 & Mild & $\begin{array}{l}\text { Freezes on starting, turning, or walking through } \\
\text { a doorway with more than one halt during any } \\
\text { of these events, but continues smoothly without } \\
\text { freezing during straight walking }\end{array}$ \\
\hline 3 & Moderate & Freezes once during straight walking \\
\hline 4 & Severe & Freezes multiple times during straight walking \\
\hline
\end{tabular}

\section{Quantitative PD gait analysis}

3.1 Clinical gait assessment

Gait analysis is considered a fundamental assistive way of distinguishing symptomatic subjects from control subjects in PD diagnostics. Disease assessment with subjective components in clinical setup is considered the gold standard for PD diagnosis. Assessment of symptoms based on questionnaires and human observation can be a significant source of misdiagnosis. The misdiagnosis rate is nearly $20 \%$, which might increase due to the lack of proper intervention of quantitative analysis. ${ }^{[26]}$ Since PD exhibits heterogenic symptom properties, continuous monitoring, and corresponding timely rehabilitation/therapy modifications are necessary. The lack of which PD subjects are prone to the burden of unwanted healthcare cost that eventually leads to the 
deprivation of QoL of an individual.

\subsection{Role of wearable sensors in gait assessment}

Conventional assessments do not capture subtle anomalies in gait characteristics, but quantitative methods do. Quantitative gait analysis techniques comprise devices that are basically of two types: Wearables ${ }^{[19,27,28]}$ and Non-Wearables. ${ }^{[29]}$

Non-wearable type signal acquisition system is commonly categorized into vision-based systems ${ }^{[30-32]}$ and instrumented walkways for PD assessment. RGB-D cameras such as MSKinect $^{[33,34]}$ and 3-D motion analysis systems ${ }^{[35]}$ have been used to capture motion data for PD analysis. For instance, a 3D gait analysis setup consists of an optometric system and a dynamometric platform equipped with piezoelectric sensors. It supports the quantification of spatiotemporal and kinematic features to investigate PD characteristics. ${ }^{[36]}$ Furthermore, instrumented walkways such as Gait Rite, and pressure mats are also employed.

However, wearable sensors are much preferred as they are light in weight, easy to carry, non-invasive, and batteryoperated, supporting real-time monitoring in an unconstrained and non-obtrusive manner. ${ }^{[37]}$ Accelerometers and pressure sensors are mostly used in developing wearable systems for PD gait analysis. The Inertial Measuring Unit (IMU) comprising the accelerometer, gyroscope, and magnetometer aids in measuring force, angular rate, and orientation of the body. Various real-time gait phase detection algorithms are developed using accelerometer-based sensor units. ${ }^{\left[{ }^{[3,39]}\right.}$ IMUbased devices are vastly in use for gait signal acquisition, ${ }^{[40,41]}$ activity classification ${ }^{[42,43]}$, and gait event identification by supervised $^{[44]}$ and unsupervised ${ }^{[45]}$ learning approaches. Ervin et al. ${ }^{[46]}$ employed a single tri-axial accelerometer to extract stride events during treadmill walking. Reliable detection of the gait events is necessary to assess the abnormalities in gait patterns due to pathology. An IMU-based approach incorporating a gyroscope is employed for accurate PD gait cycle detection. ${ }^{[4]}$ The variance in gait parameters obtained with IMU significantly discriminated PD from healthy cohorts. ${ }^{[48]}$ Nevertheless, a fall detection system using a gyroscope placed on the shank of PD subjects is developed to prevent falls by providing auditory cues. ${ }^{[49]}$

The location of the sensor placement is crucial, and it varies from trunk, ${ }^{[50,51]}$ shank, ${ }^{[39,52]}$ foot, ${ }^{[53-56]}$ lower back ${ }^{[57]}$ depending upon the type of assessment. The characterization of PD gait using accelerometer-based systems has shown promising outcomes. ${ }^{[58-60]}$ Both time and frequency domain features of accelerometry gait signals are analyzed. ${ }^{[61]}$ In a recent study, $\mathrm{PD}$ gait is detected with harmonic frequencies obtained from an inertial sensor worn on the feet. ${ }^{\text {[62] }}$ Silvia et al. ${ }^{[63]}$ quantified gait characteristics using a single triaxial accelerometer to compare them with those derived from an instrumented walkway. It is concluded that accelerometerbased body-worn monitors are well suited for gait variability and asymmetry measurements. In addition, the characterization of PD subtypes, TD, and PIGD, is also assessed using inertial sensors. ${ }^{[57]}$

Similarly, force sensors or pressure sensors embedded insole are widely used for gait abnormality recognition ${ }^{[64]}$ and gait feature extraction. ${ }^{[65]}$ The ground reaction force is measured using an insole embedded with force sensors. It is placed under the toe, metatarsal, and heel regions to obtain gait cycle reference for FoG detection. ${ }^{[66]}$ Agostini et al. ${ }^{[67]}$ detected and segmented gait cycles using footswitches to study the gait abnormalities. Similarly, PD Shoe embedded with forcesensitive resistors is used for stride identification and parameter extraction. ${ }^{[68]}$ Hence, it is noteworthy that footfall events are better determined using pressure sensors.

However, wearable sensor networks, including multiple sensors, can better analyze the PD gait aspects. As described in Gait Shoe comprising an accelerometer, gyroscope, FSR, bend sensor, etc., which can provide information in varying gait dimensions. ${ }^{[69]}$

\subsection{Gait features}

PD profoundly influences the spatiotemporal, kinetics \& kinematic parameters of gait. ${ }^{[70]}$ The typical description of gait characteristics of parkinsonism includes small shuffling steps, festination, propulsion, retropulsion, absence of arm swing, ${ }^{[71]}$ en bloc while turning, ${ }^{[72]}$ rigidity, and bradykinesia. ${ }^{[19,73]}$ The gait deteriorates with increasing motor damage quantified with UPDRS or H\&Y score. ${ }^{[36]}$

Spatiotemporal gait parameters are mostly used to differentiate PD and healthy cohort gait patterns quantitatively. All parameters are centered around each gait cycle and its subphases: stance $\&$ swing. The stance phase is when the foot is in contact with the ground, otherwise said to be in the swing phase. Stride time and swing time variability play a significant role in distinguishing PD gait from normal gait. ${ }^{[74]}$ When both limbs meet the ground at a time is said to be in the double support phase. Hence, double support time is 0 in the case of running tasks.

Following are the most prominent gait features ${ }^{[75]}$ frequently used to assess the variability, along with their corresponding range of values ${ }^{[76]}$

a) Cadence: A measure of step frequency defined as the rate at which a person walks, expressed in steps/min. On average, the cadence range for a normal gait is around 90110 steps. The cadence rate in PD goes up to a maximum of 149 steps/min. ${ }^{[77]}$

b) Gait speed: Distance covered per unit time. The gait speed of PD subjects is reduced lying within a range of 0.18 $1.21 \mathrm{~m} / \mathrm{s}^{[73]}$ compared to older adults with a gait speed of around $1.30-1.36 \mathrm{~m} / \mathrm{s} .{ }^{[78]}$

c) Step time: Duration between the heel strikes of the ipsilateral and contralateral foot. The mean step time has a value of around $0.55 \pm 0.03 \mathrm{~s}$.

d) Stride time: It is the time taken to complete one gait cycle. Specifically, defined as the duration between the heel contact of two consecutive footsteps of the same foot. It is comparatively more in PD patients with a value of $1.18 \pm$ 
$0.18 \mathrm{~s}$ than in healthy controls with $1.09 \pm 0.07 \mathrm{~s}$.

e) Step length: Distance measured between initial ground contact of the right foot and the left at an instance. Step length can vary not only due to pathological reasons but also due to age, gender, height, etc. The average step length of a normal gait is $0.61 \pm 0.21 \mathrm{~m}$. PD patients attain lesser value when compared to age-matched healthy subjects.

f) Stride length: The sum of successive left and right step lengths forms one stride length. In other words, the distance measured between the consecutive heel strikes of the same foot is termed stride length. The stride length of $1.14 \pm 0.28 \mathrm{~m}$ and $1.37 \pm 0.08 \mathrm{~m}$ is reported for PD and healthy, respectively. Stride length can be determined as a product of walking speed and stride time ${ }^{[79]}$ given by

Stride length $=$ Walking speed $\times$ Stride time

g) Step width: Distance measured laterally between feet positioned during a step event. Step width is more with a value of $0.129 \pm 0.027 \mathrm{~m}$ for PD than healthy persons. Step width provides information about postural control in gait.

The PD gait is subjected to increased stride variability with irregularity and asymmetricity. The regularity and stability measure better distinguish PD gait from age-affected gait deformities. ${ }^{[80]}$

\subsection{Gait databases}

Previous studies conducted to analyze PD gait included data from primary or secondary sources. As a primary source, gait signals are utilized from hospitals/clinics where subjects are recruited with consent to conduct experimental protocols and study the gait dynamics. Gait data freely available from the online platform act as secondary sources, which are majorly subclassified into the following:

\subsubsection{Physionet database}

Physionet is a repository of medical research resources providing access to complex physiological signals. ${ }^{[81]}$ Gait data of PD subjects are available from 3 databases in the repository.

a) Gait in Parkinson's disease database

It has a collection of Vertical Ground Reaction Force (VGRF) records measured as a function of time. It is obtained as the subjects walked for 2 min on level ground at their comfortable self-selected speed. The subjects comprise 93 PD patients and 72 healthy controls of $H \& Y$ stages $2,2.5$, and 3 . The database also includes demographics such as age, gender, height(m), weight(kg), H\&Y stage, UPDRS, UPDRSM, and walking speed during normal and dual-tasking conditions. The average age of the subjects with PD and the healthy cohort is $66.3 \pm$ 9.5 years and $63.7 \pm 8.7$ years. 59 men $\& 34$ women are in the PD group, and 40 men \& 32 women are in the healthy cohort The dataset consists of VGRF signals from three studies, ${ }^{[7,82}$ ${ }^{84]}$ differing by the type of experimental protocol conducted. Eight sensors (Ultraflex Computer Dyno Graphy, Infotronic Inc.) are located under each foot, assuming the origin is located between legs when the subject stands upright with both feet lying parallel to one another.

Each subject record contains 19 columns, timestamps as column 1, and the force generated by 16 sensors (L1-L8 \& R1R8) in columns 2-17. Columns 18 and 19 contain the total force obtained as a summation of all 8 sensors, respectively. With the available records, apart from the knowledge regarding the force as a function of time, each foot's total force record reflects the center of pressure $(\mathrm{CoP})$ transition concerning time.

b) Gait in Neurodegenerative disease database

The study record considers the subjects with 3 different neurodegenerative diseases: Parkinson's disease (PD), Huntington's Disease (HD), and Amyotrophic Lateral sclerosis (ALS) with 15, 20, and 13 subjects respectively, along with 16 healthy control subjects. Force-sensitive resistors are employed to obtain output that roughly represents the force applied by the foot.

It contains the time series duration of various phases of gait cycles: Stride time, swing time of both limbs, and double support intervals. The description file of PD subjects includes information regarding age, gender, walking speed, weight, height, and $\mathrm{H} \& \mathrm{Y}$ as disease severity measures.

c) Gait in aging and disease database

The database contains stride interval records of 15 subjects, categorized into healthy, old, and PD. The age of healthy adults in the young category is 23-29 years, whereas healthy old adults are in the range of 71-77 years of age. Five older adults 60-77 years old with Parkinson's disease have also been included. PD subjects walked around an obstacle-free hallway for 6 minutes wearing shoes embedded with ultra-thin forcesensitive resistors. Each subject record contains 2 columns, elapsed time, and corresponding stride interval.

\subsubsection{Parkinson's Progressive Markers Initiative (PPMI)}

PPMI is a longitudinal cohort study funded by the Michael $\mathrm{J}$. Fox foundation for Parkinson's research. Gait assessment is a sub-study conducted within the PPMI genetic cohort project. ${ }^{[85-88]}$ The study uses a data acquisition system comprising wearable sensors to measure temporal gait parameters. The measuring unit is an accelerometer-based component, held within a custom-made Velcro belt, worn on both the lower back and the wrists to measure the acceleration of movements. Gait features are extracted by performing 6 different assessment tests that include the usual walk in a selfselected pace, sway test, and timed up \& go test.

The features mentioned in Table 6 characterize the rhythmicity, consistency, and smoothness in the tasks performed in both single and dual-tasking conditions.

\section{Machine learning approach in PD diagnosis}

Machine learning-based models have numerous computeraided diagnostics applications that are likely to aid timely medications and disease management in the future. Researchers used various ML techniques for PD assessment to identify the abnormalities in the underlying gait patterns and 
their association with disease severity measures.

Table 6. Gait parameters in Parkinson's Progressive Markers Initiative (PPMI) database.

\begin{tabular}{|c|c|c|}
\hline Category & \multicolumn{2}{|c|}{ Features } \\
\hline \multirow[t]{4}{*}{ Sway } & 1) & Velocity $(\mathrm{mm} / \mathrm{s})$ \\
\hline & 2) & Sway path $(\mathrm{mm})$ \\
\hline & 3) & Centroid frequency $(\mathrm{Hz})$ \\
\hline & 4) & Jerk $\left(\mathrm{m}^{2} / \mathrm{s}^{5}\right)$ \\
\hline \multirow{6}{*}{$\begin{array}{l}\text { Timed Up and } \\
\text { Go }\end{array}$} & 1) & TUG Duration (s) \\
\hline & 2) & Number of steps \\
\hline & 3) & $\begin{array}{l}\text { Average step duration during the } \\
\text { straight walk (s) }\end{array}$ \\
\hline & 4) & Average step duration during turns (s) \\
\hline & 5) & Step regularity \\
\hline & 6) & Step symmetry \\
\hline \multirow[t]{7}{*}{ Walking } & 1) & Walk speed $(\mathrm{m} / \mathrm{s})$ \\
\hline & 2) & Cadence (steps/min) \\
\hline & 3) & Average stride time (s) \\
\hline & 4) & Stride CV $(\%)$ \\
\hline & 5) & Step regularity \\
\hline & 6) & Step symmetry \\
\hline & 7) & Jerk $\left(\operatorname{deg} /^{\beta}\right)$ \\
\hline \multirow[t]{8}{*}{ Arm swing } & 1) & Amplitude_Right_arm (deg) \\
\hline & 2) & Amplitude_Left_arm (deg) \\
\hline & 3) & Variability_Right_arm (\%) \\
\hline & 4) & Variability_Left_arm (\%) \\
\hline & 5) & Symmetry Right/Left \\
\hline & 6) & Jerk Right $\left(\operatorname{deg} /{ }^{3}\right)$ \\
\hline & 7) & Jerk Left $\left(\operatorname{deg} /{ }^{3}\right)$ \\
\hline & 8) & Asymmetry_index \\
\hline \multirow[t]{2}{*}{ Axial } & 1) & Trunk Rotation Asymmetry (\%) \\
\hline & 2) & Average Amplitude trunk (deg) \\
\hline
\end{tabular}

$\overline{\mathrm{mm}}=$ millimetre, $\mathrm{s}=$ Seconds, $\mathrm{Hz}=$ Hertz; $\mathrm{m}=$ metre, deg $=$ degree

A broad categorization of the ML approach is based on the underlying learning approach, namely, supervised and unsupervised. Various supervised and unsupervised ML algorithms are used in different facets of PD and evolved over the years, bringing in novel insights to improve overall efficiency. The following subsections present the current state of art gait analysis-based PD diagnostic research works majorly carried out. Table 7 portrays the significant features of the relevant research works discussed in the following sections. It includes various parameters that give information on the database or data acquisition systems used, the number of samples considered, gait features, algorithms employed, and the key findings.

\subsection{Classification of PD and healthy subjects}

Classification of PD and healthy cohorts based on their gait patterns is a much-carried-out research area. Ground reaction force measured while walking has been of interest for gait analysis. Khoury et al. ${ }^{[89]}$ present a detailed study of supervised and unsupervised ML methodologies in PD diagnostics using VGRF data. It is reported that supervised algorithms performed better than unsupervised ones. But due to sample imbalance, misclassification occurred in distinguishing healthy persons from patients in the initial stage of PD. Khorasani and Daliri ${ }^{[00]}$ used the Hidden Markov Model (HMM) with Gaussian Mixtures to discriminate PD and control gait. Stride interval parameters derived from VGRF signals yielded a classification accuracy rate of $90.3 \%$. Similarly, the information regarding load distribution while walking is utilized for PD gait classification. Correlation properties are employed and reported 95\% overall classification accuracy with linear decision boundary. ${ }^{[91]}$ The support Vector Machine (SVM) algorithm is most commonly used for classifying the PD \& Control subjects. ${ }^{[92-96]} \mathrm{H}$. Jeon et al. ${ }^{[97]}$ explored the SVM's classification ability in PD diagnosis using the spatial-temporal image of plantar pressure. A classification accuracy of $91.37 \%$ is obtained with Radial Basis Function (RBF) kernel. Alam MN et al. ${ }^{[98]}$ selected swing time, stride time variability, and center of pressure as relevant features using the sequential forward feature selection method for classification. SVM with cubic-kernel outperformed K-NN, Random Forest (RF), and decision tree classifiers with an accuracy of $93.6 \%$. Gait features such as swing time, stance time, stride time, and foot strike profile have provided a classification accuracy rate of $92.7 \%$ for PD diagnosis. ${ }^{[99]}$ Tremor characteristics are also considered thereby, indicating the scope for a multimodal approach. J Camilo et al. incorporated handwriting and speech modalities with gait for multimodal assessment of PD. ${ }^{[100]}$

Deep learning approaches such as artificial neural network $(\mathrm{ANN}),{ }^{[101]}$ deep neural network $(\mathrm{DNN}),{ }^{[102]}$ convolutional neural network $(\mathrm{CNN})^{[100,103]}$ have shown promising results in PD assessment. VGRF data was acquired from 12 PD and 20 healthy subjects and conducted a statistical analysis to determine the best parameters for ANN-based classifiers. Kinetic, kinematic, and basic gait parameters such as walking pace, step length, and knee angle are determined as prominent features. ${ }^{[104]}$ Zeng et al. ${ }^{[105]}$ proposed radial basis function neural networks to learn the PD gait dynamics of $93 \mathrm{PD}$ and 73 healthy controls. A classification accuracy of $96.39 \%$ is obtained with sensitivity and specificity of $96.77 \%$ and $95.89 \%$, respectively.

Moreover, stride intervals obtained from VGRF signals of gait in neurodegenerative disease database have been employed with LDA, ${ }^{[106]}$ Random Forest using TMA framework, ${ }^{[107]} \mathrm{SVM},{ }^{[108]} \mathrm{HMM},{ }^{[90]}$ Decision tree ${ }^{[109]}$ to discriminate PD from HD, ALS, and healthy subjects. Khoury et al. ${ }^{[89]}$ obtained $90 \%$ accuracy in differentiating PD from ALS, HD, and healthy groups with a K-NN classifier. Likewise, IMU-based gait parameters classified 4 types of neurological diseases with an SVM classifier. ${ }^{[52]}$ 
Table 7. Various parameters of research work were carried out for PD analysis based on gait characteristics using ML algorithms.

\begin{tabular}{|c|c|c|c|c|c|}
\hline Author & $\begin{array}{l}\text { Database/Data } \\
\text { acquisition system }\end{array}$ & $\begin{array}{l}\text { No. } \\
\text { samples }\end{array}$ & Gait features & Algorithms & Findings \\
\hline Khoury et al. ${ }^{[89]}$ & Physionet & $\begin{array}{l}93 \text { PD } \\
72 \text { Healthy }\end{array}$ & $\begin{array}{l}\text { Spatiotemporal } \\
\text { parameters }\end{array}$ & $\begin{array}{l}\text { K-NN, Decision } \\
\text { Tree (DT), RF, } \\
\text { Naïve Bayes } \\
\text { (NB), SVM, K- } \\
\text { Means, GMM }\end{array}$ & $\begin{array}{l}\text { Supervised algorithms } \\
\text { performed better than } \\
\text { unsupervised ones. } \\
\text { Obtained } 90 \% \text { accuracy in } \\
\text { differentiating PD from ALS, } \\
\text { HD \& Healthy groups. }\end{array}$ \\
\hline $\begin{array}{l}\text { Khorasani and } \\
\text { Daliri }^{[90]}\end{array}$ & Physionet & $\begin{array}{l}15 \text { PD } \\
16 \text { Healthy }\end{array}$ & Stride interval parameters & HMM & $90.3 \%$ accuracy rate \\
\hline Alkhatib et al. ${ }^{[91]}$ & Physionet & $\begin{array}{l}29 \text { PD } \\
18 \text { Healthy }\end{array}$ & COP, Load distribution & LDA & $\begin{array}{l}95 \% \text { overall classification } \\
\text { accuracy with the linear } \\
\text { decision boundary. }\end{array}$ \\
\hline H. Jeon et al. ${ }^{[97]}$ & $\begin{array}{l}\text { Foot-pressure } \\
\text { system }\end{array}$ & $\begin{array}{l}21 \text { PD } \\
17 \text { Healthy }\end{array}$ & $\begin{array}{l}\text { Spatial-temporal image of } \\
\text { plantar pressure }\end{array}$ & SVM & $\begin{array}{l}\text { The overall accuracy of } 91.7 \% \\
\text { with RBF kernel. }\end{array}$ \\
\hline Alam MN et al. ${ }^{[98]}$ & Physionet & $\begin{array}{l}29 \text { PD } \\
18 \text { Healthy }\end{array}$ & $\begin{array}{l}\text { Swing time, stride time } \\
\text { variability, and center of } \\
\text { pressure }\end{array}$ & $\begin{array}{l}\text { SVM, K-NN, } \\
\text { RF }\end{array}$ & $\begin{array}{l}\text { SVM with cubic-kernel } \\
\text { outperformed K-NN, RF, and } \\
\text { decision tree classifiers with } \\
\text { an accuracy of } 93.6 \% \text {. }\end{array}$ \\
\hline Abdulhay et al. ${ }^{[99]}$ & Physionet & $\begin{array}{l}93 \text { PD } \\
72 \text { Healthy }\end{array}$ & $\begin{array}{l}\text { Swing time, stance time, } \\
\text { stride time, and foot strike } \\
\text { profile }\end{array}$ & SVM & $\begin{array}{l}\text { The classification accuracy } \\
\text { rate of } 92.7 \% \text { for PD } \\
\text { diagnosis. }\end{array}$ \\
\hline T. Nooritawati ${ }^{[101]}$ & $\begin{array}{l}\text { Force plates, } \\
\text { reflective markers, } \\
\text { infrared camera }\end{array}$ & $\begin{array}{l}12 \text { PD } \\
20 \text { Healthy }\end{array}$ & $\begin{array}{lr}\text { Basic } & \text { Spatiotemporal } \\
+ \text { Kinetic } & \text { +Kinematics } \\
\text { parameters } & \end{array}$ & SVM, ANN & $\begin{array}{l}\text { SVM performed better than } \\
\text { ANN with the fusion of } \\
\text { Spatio-temporal \& kinetic } \\
\text { parameters resulting in } 98.2 \% \\
\text { accuracy. }\end{array}$ \\
\hline I. El Maachi ${ }^{[102]}$ & Physionet & $\begin{array}{l}93 \text { PD } \\
72 \text { Healthy }\end{array}$ & $\begin{array}{l}\text { Raw Left, Right \& Total } \\
\text { VGRF signals }\end{array}$ & DNN & $\begin{array}{l}\text { PD severity (UPDRS) was } \\
\text { predicted with } 85.3 \% \\
\text { accuracy and } 98.7 \% \text { in PD } \\
\text { classification. }\end{array}$ \\
\hline Y. Xia ${ }^{[103]}$ & Physionet & $\begin{array}{l}93 \text { PD } \\
72 \text { Healthy }\end{array}$ & $\begin{array}{l}\text { Spatial \& } \quad \& \quad \text { temporal } \\
\text { features }\end{array}$ & LSTM, CNN & $\begin{array}{l}99.01 \% \text { accuracy with the } \mathrm{Si} \\
\text { dataset in H\&Y stage } \\
\text { prediction whereas } 99.31 \% \\
\text { accuracy with Ga dataset. } \\
\text { Also, DCALSTM performed } \\
\text { better than DCNN and } \\
\text { DALSTM separately. }\end{array}$ \\
\hline H. Manap et al. ${ }^{[104]}$ & $\begin{array}{l}\text { Force plates, } \\
\text { reflective markers, } \\
\text { infrared camera }\end{array}$ & $\begin{array}{l}12 \text { PD } \\
20 \text { Healthy }\end{array}$ & $\begin{array}{l}\text { Walking pace, step length, } \\
\text { knee angle, the vertical } \\
\text { parameter of ground } \\
\text { reaction force }\end{array}$ & ANN & $\begin{array}{l}95.63 \% \text { classification } \\
\text { accuracy obtained with } \\
\text { selected gait parameters }\end{array}$ \\
\hline Zeng et al. ${ }^{[105]}$ & Physionet & $\begin{array}{l}93 \text { PD } \\
72 \text { Healthy }\end{array}$ & $\begin{array}{l}\text { Difference between the } \\
\text { outputs of the L3 and R3 } \\
\text { sensors, L6 and R6 } \\
\text { sensors, Sum of the eight } \\
\text { sensor outputs from the } \\
\text { left and right foot. }\end{array}$ & RBF-NN & $\begin{array}{l}\text { A classification accuracy of } \\
96.39 \% \text { is obtained with } \\
\text { sensitivity and specificity of } \\
96.77 \% \text { and } 95.89 \% \text {, } \\
\text { respectively. }\end{array}$ \\
\hline A.K. Bhoi ${ }^{[106]}$ & Physionet & $\begin{array}{l}15 \text { PD } \\
15 \text { Healthy }\end{array}$ & $\begin{array}{l}\text { Foot-Frequency domain } \\
\text { power }\end{array}$ & LDA, K-Means & $\begin{array}{l}\text { The energy power domain } \\
\text { feature can be considered a } \\
\text { noticeable parameter in gait } \\
\text { dynamic study. }\end{array}$ \\
\hline
\end{tabular}


Continued

\begin{tabular}{|c|c|c|c|c|c|}
\hline Author & $\begin{array}{l}\text { Database/Data } \\
\text { acquisition system }\end{array}$ & No. of samples & Gait features & Algorithms & Findings \\
\hline Y.Yan et al..$^{[107]}$ & Physionet & $\begin{array}{l}15 \text { PD } \\
16 \text { Healthy }\end{array}$ & $\begin{array}{l}\text { Topological feature-set } \\
\text { generated from time } \\
\text { series. }\end{array}$ & $\begin{array}{l}\text { RF using the } \\
\text { TMA } \\
\text { framework }\end{array}$ & $\begin{array}{l}\text { An AUC score of } 0.9667 \text { is } \\
\text { obtained in comparing PD to } \\
\text { healthy controls. }\end{array}$ \\
\hline M.R. Daliri ${ }^{[108]}$ & Physionet & $\begin{array}{l}15 \text { PD } \\
16 \text { Healthy }\end{array}$ & $\begin{array}{l}\text { Features extracted from } \\
\text { left swing interval, double } \\
\text { support interval, and left } \\
\text { stance interval. }\end{array}$ & SVM & $\begin{array}{l}\text { An accuracy of } 89.33 \% \text { was } \\
\text { obtained with PD. }\end{array}$ \\
\hline Zia et al..$^{[110]}$ & Accelerometer & $\begin{array}{l}81 \text { PD } \\
61 \text { Healthy }\end{array}$ & $\begin{array}{l}\text { Spatiotemporal \& Signal } \\
\text { based gait parameters }\end{array}$ & $\begin{array}{l}\text { Partial least } \\
\text { square- } \\
\text { discriminant } \\
\text { analysis }\end{array}$ & $\begin{array}{l}\text { Highlights the significance of } \\
\text { signal-based gait properties } \\
\text { for early-stage PD } \\
\text { classification. }\end{array}$ \\
\hline Rehman et al..$^{[111]}$ & GAITRite & $\begin{array}{l}119 \mathrm{PD} \\
184 \mathrm{HC}\end{array}$ & $\begin{array}{l}\text { Mean step velocity, mean } \\
\text { step length, step length } \\
\text { variability, mean step } \\
\text { width, and step width } \\
\text { variability }\end{array}$ & RF, SVM, LR & $\begin{array}{l}\text { Identified gait features can aid } \\
\text { in early-stage PD } \\
\text { classification. }\end{array}$ \\
\hline Rehman et al..$^{[112]}$ & $\begin{array}{l}\text { GAITRite, } \\
\text { Accelerometer }\end{array}$ & $\begin{array}{l}93 \text { PD } \\
103 \text { Control }\end{array}$ & $\begin{array}{l}\text { Pace, rhythm, variability, } \\
\text { asymmetry, postural } \\
\text { control parameters of gait }\end{array}$ & SVM, RF & $\begin{array}{l}\text { Model performance is higher } \\
\text { with accelerometer data than } \\
\text { GAITRite. }\end{array}$ \\
\hline F. Wahid et al..$^{[113]}$ & $\begin{array}{l}\text { Instrumented } \\
\text { force platforms, } 8- \\
\text { camera } \quad \text { video } \\
\text { motion analysis } \\
\text { system }\end{array}$ & $\begin{array}{l}23 \mathrm{PD} \\
26 \quad \text { Age- } \\
\text { matched } \\
\text { control }\end{array}$ & $\begin{array}{l}\text { Spatiotemporal } \\
\text { features }\end{array}$ & $\begin{array}{l}\text { KFD, BA, } \\
\text { KNN, SVM, RF }\end{array}$ & $\begin{array}{l}\text { Before normalization- } 80 \% \\
\text { After normalization- } 92.6 \%\end{array}$ \\
\hline $\begin{array}{l}\text { T. D. Pham and H. } \\
\text { Yan }^{[114]}\end{array}$ & Physionet & $\begin{array}{l}93 \text { PD } \\
72 \text { Healthy }\end{array}$ & $\begin{array}{l}\text { Tensor decomposition } \\
\text { features }\end{array}$ & LS-SVM & $\begin{array}{l}\text { Tensor decomposition factors } \\
\text { of time-series data can be } \\
\text { considered effective features } \\
\text { and potential physiological } \\
\text { markers of PD. }\end{array}$ \\
\hline F. Parisi et al. ${ }^{[115]}$ & IMU & $34 \mathrm{PD}$ & $\begin{array}{l}\text { Kinematic features in time } \\
\& \text { frequency domain. }\end{array}$ & $\begin{array}{l}\text { Nearest } \\
\text { Centroid } \\
\text { Classifier } \\
\text { (NCC), K-NN, } \\
\text { SVM }\end{array}$ & $\begin{array}{l}\text { K-NN has shown the lowest } \\
\text { classification error }\end{array}$ \\
\hline Balaji et al..$^{[116]}$ & Physionet & $\begin{array}{l}93 \text { PD } \\
72 \text { Healthy }\end{array}$ & $\begin{array}{l}\text { Spatiotemporal gait } \\
\text { parameters }\end{array}$ & $\begin{array}{l}\text { K-NN, SVM, } \\
\text { Ensemble, } \\
\text { Naïve Bayes, } \\
\text { classifier (EC), }\end{array}$ & $\begin{array}{l}\text { Classification accuracy of } \\
98.4 \% \text { in } \mathrm{H} \& \mathrm{Y} \text { stage } \\
\text { classification. }\end{array}$ \\
\hline Balaji et al..$^{[117]}$ & Physionet & $\begin{array}{l}93 \text { PD } \\
72 \text { Healthy }\end{array}$ & Kinematic gait features & LSTM & $\begin{array}{l}\text { Classification accuracy of } \\
96.6 \% \text { in multi-class } \\
\text { classification and } 98.6 \% \text { in } \\
\text { binary classification. }\end{array}$ \\
\hline $\begin{array}{l}\text { A. S Alharthi and } \\
\text { A.J. Casson }{ }^{[118]}\end{array}$ & Physionet & $\begin{array}{l}93 \text { PD } \\
72 \text { Healthy }\end{array}$ & $\begin{array}{l}\text { Spatiotemporal } \\
\text { parameters }\end{array}$ & DCNN & $\begin{array}{l}\text { Analyze VGRF signals and } \\
\text { resulted in } 95.5 \% \text { mean } \\
\text { performance } \\
\text { F1-score for } \\
\text { effective }\end{array}$ \\
\hline
\end{tabular}


Continued

\begin{tabular}{|c|c|c|c|c|c|}
\hline Author & $\begin{array}{l}\text { Database/Data } \\
\text { acquisition system }\end{array}$ & No. of samples & Gait features & Algorithms & Findings \\
\hline Zhao et al..$^{[119]}$ & Physionet & $\begin{array}{l}93 \text { PD } \\
72 \text { Healthy }\end{array}$ & $\begin{array}{l}\text { Spatiotemporal gait } \\
\text { parameters }\end{array}$ & LSTM, CNN & $\begin{array}{l}\text { Prediction accuracy is } \\
\text { improved with the CNN- } \\
\text { LSTM hybrid approach than } \\
\text { individual model accuracies. }\end{array}$ \\
\hline $\begin{array}{l}\text { T. Aşuroğlu et } \\
\text { al. }^{[120]}\end{array}$ & Physionet & $\begin{array}{l}93 \text { PD } \\
72 \text { Healthy }\end{array}$ & $\begin{array}{l}16 \text { time-domain \& } 7 \\
\text { frequency-domain } \\
\text { features. }\end{array}$ & $\begin{array}{l}\text { Locally } \\
\text { Weighted } \\
\text { Random Forest } \\
\text { (LWRF) }\end{array}$ & $\begin{array}{l}\text { LWRF approach reduces the } \\
\text { interpatient variability by } \\
\text { assigning weights to each } \\
\text { sample; hence, a better } \\
\text { correlation of prediction with } \\
\text { clinical measures }\end{array}$ \\
\hline $\begin{array}{l}\text { C. Caramia et } \\
\text { al. }{ }^{[121]}\end{array}$ & IMU & $\begin{array}{l}25 \mathrm{PD} \\
25 \quad \text { Age- } \\
\text { matched } \\
\text { control }\end{array}$ & $\begin{array}{l}\text { Range of Motion (RoM) } \\
\text { and Spatiotemporal } \\
\text { parameters }\end{array}$ & SVM & $\begin{array}{l}\text { Higher accuracies were } \\
\text { obtained with RoM and } \\
\text { spatiotemporal parameters } \\
\text { combined }\end{array}$ \\
\hline $\begin{array}{l}\text { Kostić, Vladimir } \\
\text { S. et al. }{ }^{[66]}\end{array}$ & IMU & $12 \mathrm{PD}$ & Stride parameters & $\begin{array}{l}\text { Rule-based } \\
\text { classification }\end{array}$ & $\begin{array}{l}\text { Stride classification of FOG } \\
\text { with tremor (FOG+) and FOG } \\
\text { with a complete motor block } \\
\text { (FOG+) attains } 100 \% \\
\text { accuracy. }\end{array}$ \\
\hline $\begin{array}{l}\text { Nader Naghavi et } \\
\text { al. }{ }^{[122]}\end{array}$ & Accelerometers & $18 \mathrm{PD}$ & $\begin{array}{l}\text { Freeze index, Sample } \\
\text { Entropy, Power, Standard } \\
\text { Deviation }\end{array}$ & $\begin{array}{l}\text { SVM, K-NN, } \\
\text { MLP }\end{array}$ & $\begin{array}{l}\text { SVM, K-NN, and MLP } \\
\text { formed an ensemble classifier } \\
\text { using bagging techniques, } \\
\text { identified } 97.4 \% \text { of FOG } \\
\text { events, and predicted } 66.7 \% \text { of } \\
\text { events. }\end{array}$ \\
\hline Y. Zhang et al..$^{[123]}$ & Accelerometers & $12 \mathrm{PD}$ & $\begin{array}{l}\text { Signal \& statistical } \\
\text { features: FI, variance, and } \\
\text { dominant frequency. } \\
\text { Temporal gait \& balance } \\
\text { features Cadence, } \\
\text { acceleration RMS, step } \\
\text { regularity, gait pattern, } \\
\text { variability, and Harmonic } \\
\text { Ratio. }\end{array}$ & AdaBoostC4.5 & $\begin{array}{l}\text { Cadence, gait regularity, and } \\
\text { variability measures } \\
\text { performed better than the } \\
\text { other statistical signal } \\
\text { parameters predicting the pre- } \\
\text { FoG phase }\end{array}$ \\
\hline $\begin{array}{l}\text { F. Demrozi et } \\
\text { al. }{ }^{[124]}\end{array}$ & DAPHNET & $10 \mathrm{PD}$ & Statistical features & $\mathrm{K}-\mathrm{NN}$ & $\begin{array}{l}\text { A sensitivity of } 94.1 \% \text { and } \\
\text { specificity of } 97.1 \% \text { are } \\
\text { reported for identifying the } \\
\text { pre-FoG phase }\end{array}$ \\
\hline
\end{tabular}

On the other hand, accelerometry-based gait features and the need for standardization is described ${ }^{[112]} \mathrm{F}$. Wahid $e t$ combined with signal-based characteristics are quantified to classify the PD group. ${ }^{[110]}$ Although accelerometers are widely used, missing data is a matter of concern in remote monitoring. John P et al. ${ }^{[125]}$ developed a multi-source ensemble learning combined with $\mathrm{CNN}$ to incorporate the patient records with incomplete data and improve prediction accuracy.

In addition, GAITRite is employed to quantify and identify the optimal gait characteristics using a recursive feature elimination technique. ${ }^{[111]}$ The effect of varying experimental walking protocols on ML-based classification is made evident, $a l .{ }^{[113]}$ proposed multiple regression normalization approaches to differentiate spatiotemporal gait among PD and healthy subjects significantly. Random forest classifier reported an improved classification accuracy of $92.6 \%$ using normalized data. A tensor decomposition approach resulted in a sensitivity and specificity of $100 \%$ in discriminating multi-sensor timeseries gait characteristics. ${ }^{[14]}$ Peng et al. ${ }^{[126]}$ introduced a multivariate approach to constructing gait influence diagrams (GID) to analyze the PD gait patterns. As per the findings, gait asymmetry is evident in the anterior-posterior and 
mediolateral directions. Thus, analyzing gait in different facets by choosing appropriate means of assessment can improve overall efficiency.

\subsection{PD severity detection}

Machine learning-based tools are further used to determine the disease severity level. PD severity is majorly evaluated based on UPDRS scores ${ }^{[115]}$ and $\mathrm{H} \& \mathrm{Y}$ stages.

The Physionet database is utilized commonly for rating the PD severity with ML techniques. Recently, Balaji et al., ${ }^{[116]}$ presented a data-driven approach for H\&Y stage-level classification using supervised ML algorithms. SVM outperformed other algorithms with an accuracy of $98.4 \%$ employing correlation-based feature extraction methods. DNN-based classifiers are also utilized in various PD-related studies for severity rating. A categorization of PD severity level based on UPDRS and H\&Y scales is performed using LSTM networks resulting in $96.6 \%$ accuracy ${ }^{[117]} \mathrm{A}$. S Alharthi and A.J. Casson ${ }^{[118]}$ adapted Layer wise Relevance Propagation (LRP) approach to analyze VGRF signals and resulted in a $95.5 \%$ mean performance $\mathrm{F} 1$-score for effective severity classification. 1-D CNN is used to build DNN that processes 18 1-D VGRF signals parallelly to predict the PD severity based on UPDRS, resulting in $85.3 \%$ accuracy. ${ }^{[102]} \mathrm{A}$. Turner \& S. Hayes ${ }^{[127]}$ examined the capability of LSTM and $\mathrm{CNN}$ in gait diagnostics. A dual-modal deep learning approach comprising CNN and LSTM is used for PD severity detection using VGRF signals. In, ${ }^{[119]}$ a two-channel model consisting of 2-layer LSTM and 5-layer CNN is employed to capture the spatiotemporal parameters of PD subjects. The feature vectors from LSTM and CNN are fed to the Softmax classifier. It is observed that the prediction accuracy is improved with the CNN-LSTM hybrid approach than individual model accuracies. Similarly, dual-modal attention-enhanced DCALSTM performed better than DCNN and DALSTM. ${ }^{[103]}$ A hybrid approach named Locally Weighted Random Forest (LWRF) is utilized for regression analysis using a similar dataset to predict UPDRS and H\&Y scores. ${ }^{[120]}$ LWRF approach reduces the interpatient variability by assigning weights to each sample; hence, a better correlation of prediction with clinical measures. A correlation coefficient (CC) of 0.960 , mean absolute error (MAE) of 0.168 , and root mean square error (RMSE) of 0.306 resulted in severity prediction in terms of H\&Y scaling. Nevertheless, IMU-based grading of PD severity level is also studied, emphasizing the influence of sensor location in parameter estimation. Higher accuracies were obtained with RoM and spatiotemporal parameters combined. ${ }^{[121]}$

\subsection{Freezing of gait detection}

FoG is an extreme form of gait disorder characterized by an episodic cessation of gait accompanied by festination or leg trembling. ${ }^{[128]}$ FoG co-occurring with impaired balance while walking can be a reason for sudden falls and associated injuries. Researchers attempt to build numerous ML-based
FoG detection ${ }^{[66,129,130]}$ and prediction models. ${ }^{[122,131,132]}$ However, prediction models with low latency are preferred as the subjects could make timely postural adjustments. As the FoG episodes are predicted in advance, it enables preemptive cueing, thereby preventing falls.

Impaired gait patterns are found to be more informative in FoG prediction as compared to conventional FoG features. Cadence, gait regularity and variability measures performed better than the other statistical signal parameters predicting the pre-FoG phase. ${ }^{[123]}$ Tri-axial accelerometer-based gait monitoring systems are worn on the back, hip, and ankle. A sensitivity of $94.1 \%$ and specificity of $97.1 \%$ are reported for identifying the pre-FoG phase using the DAPHNET database with the K-NN algorithm. ${ }^{[124]}$ A subject-independent FoG detection system is developed against the typical subjectdependent systems using a similar dataset. ${ }^{[133]}$

PD patients subjected to cueing techniques have shown a shortening in the FoG duration ${ }^{[129]}$ and the number of freezing episodes. ${ }^{[134]}$ Providing visual cues upon FoG detection improved the gait speed and stride length of PD subjects. ${ }^{[135]} \mathrm{A}$ biofeedback cueing approach is integrated with an FoG detection system, ${ }^{[136]}$ trained using neural networks for realtime adaptive monitoring. Thus, it is noteworthy that a wearable system that can predict and provide timely cues prevents severe impact, ultimately avoiding injuries.

\section{Conclusion \& future perspective}

This paper presents the significance of gait monitoring in PD diagnosis. Studying the abnormalities in gait patterns to determine the underlying pathology is important and is of great research interest. Meanwhile, wearable sensor technologies are replacing conventional means in clinical diagnosis. From a clinical aspect, a definite medication to completely cure or prevent PD is yet to be obtained. Even though L-Dopa-like medications help in managing the symptoms, it is not a persistent remedy. For now, debilitating symptoms are managed by rehabilitation, external assistance, therapies, etc. Thus, real-time monitoring of subjects can help keep track of the patient's physical condition and wellbeing. Sensor data collected on a real-time basis can support the computer-assisted diagnosis, simplifying the clinician's decision-making process.

Extensive research is performed to discriminate $\mathrm{PD}$ subjects from healthy cohorts using various machine learning techniques. Furthermore, models that can predict the PD severity level following UPDRS or H\&Y scores are also developed. But the generalizability of these developed models is compromised due to reduced intersubject variability. Due to the lesser number of training samples, the out-of-sample accuracy is reduced. Increasing the training samples with distinct characteristics can better classify age-matched older adults and PD patients.

Also, the severity level can be predicted better if different dimensions of a modality are particularly observed. The literature presents numerous wearable systems that are 
suitable for uninterrupted real-time gait monitoring. Accelerometers, force-sensitive resistors, and gyroscopes are widely used for gait data acquisition. Identifying ways to merge them to understand every aspect of PD gait better is also a great means of improving the prediction. Moreover, a singlemodal approach could be reinforced by considering a multimodal approach that can eventually support early PD detection.

\section{Acknowledgment}

I would like to acknowledge the Department of Science and Technology (DST), Govt. of India, funded project SEED/TIDE/2018/37.

\section{Conflict of interest}

There are no conflicts to declare.

\section{Supporting information}

Not Applicable.

\section{References}

[1] J. Parkinson, Journal of neuropsychiatry and clinical neurosciences, 2002, 14, 223-236.

[2] O. Hornykiewicz, Journal of Neural Transmission, 2006, 70, 9-15, doi: 10.1007/978-3-211-45295-0_3.

[3] G. C. Cotzias, P. S. Papavasiliou, R. Gellene, New England Journal of Medicine, 1969, 280, 337-345, doi: 10.1056/nejm196902132800701.

[4] J. Jankovic, J Neurol Neurosurg Psychiatry, 2008, 79, 368376, doi: 10.1136/jnnp.2007.131045.

[5] P. Rizek, N. Kumar, M. S. Jog, Canadian Medical Association Journal, 2016, 188, 1157-1165, doi: 10.1503/cmaj.151179.

[6] D. E. Lilienfeld, D. P. Perl, Neuroepidemiology, 1993, 12, 219-228, doi: 10.1159/000110320.

[7] W. Yang, J. L. Hamilton, C. Kopil, J. C. Beck, C. M. Tanner, R. L. Albin, E. Ray Dorsey, N. Dahodwala, I. Cintina, P. Hogan, T. Thompson, External Resources Crossref, 2020, 6, 15, doi: 10.1038/s41531-020-0117-1.

[8] S. Y.-Y. Pang, P. W.-L. Ho, H.-F. Liu, C.-T. Leung, L. Li, E. E. S. Chang, D. B. Ramsden, S.-L. Ho, Translational Neurodegeneration, 2019, 8, 23, doi: 10.1186/s40035-019-01659.

[9] G. F. Wooten, L. J. Currie, V. E. Bovbjerg, J. K. Lee, J. Patrie, J Neurol Neurosurg Psychiatry. 2004, 75, 637-639, doi: 10.1136/jnnp.2003.020982.

[10] W. Muangpaisan, H. Hori, C. Brayne, Journal of Epidemiology, 2009, 19, 281-293, doi: 10.2188/jea.je20081034.

[11] D. M. Radhakrishnan, V. Goyal, Neurology India, 2018, 66 , 26.

[12] A. Schrag, J. M. Schott, The Lancet Neurology, 2006, 5, $355-$ 363, doi: 10.1016/s1474-4422(06)70411-2.

[13] H. Zach, M. Dirkx, B. R. Bloem, R. C. Helmich, Journal of Parkinson's Disease, 2015, 5, 471-474, doi: 10.3233/jpd-150650. [14] A. J. Hughes, S. E. Daniel, S. Blankson, A. J. Lees, Archives of Neurology, 1993, 50, 140-148, doi: 10.1001/archneur.1993.00540020018011.

[15] P. G. Wasielewski, J. M. Burns, W. C. Koller, Movement Disorders, 2008, 13, 90-100, doi: 10.1002/mds.870131316.

[16] J. Massano, K. P. Bhatia, Cold Spring Harb Perspect Med., 2012, 2, 1-15, doi: 10.1101/cshperspect.a008870.

[17] A. Berardelli, J. C. Rothwell, P. D. Thompson, M. Hallett, Brain, 2001, 124, 2131-2146, doi: 10.1093/brain/124.11.2131.

[18] P.-H. Chen, R.-L. Wang, D.-J. Liou, J.-S. Shaw, International Journal of Gerontology, 2013, 7, 189-193, doi: 10.1016/j.ijge.2013.03.005.

[19] S. Chen, J. Lach, B. Lo, G.-Z. Yang, IEEE Journal of Biomedical and Health Informatics, 2016, 20, 1521-1537, doi: 10.1109/jbhi.2016.2608720.

[20] M. E. Micó-Amigo, I. Kingma, S. Heinzel, S. M. Rispens, T. Heger, S. Nussbaum, R. C. van Lummel, D. Berg, W. Maetzler, J. H. van Dieën, Frontiers in Human Neuroscience, 2019, 13, 59, doi: 10.3389/fnhum.2019.00059.

[21] S. del Din, M. Elshehabi, B. Galna, M. A. Hobert, E. Warmerdam, U. Suenkel, K. Brockmann, F. Metzger, C. Hansen, D. Berg, L. Rochester, W. Maetzler, Annals of Neurology, 2019, 86, 357-367, doi: 10.1002/ana.25548.

[22] M. Belić, V. Bobić, M. Badža, N. Šolaja, M. Đurić-Jovičić, V. S. Kostić, Clin Neurol Neurosur, 2019, 184, 105442, doi: 10.1016/j.clineuro.2019.105442.

[23] A. J. Hughes, S. E. Daniel, L. Kilford, A. J. Lees, Journal of Neurology, Neurosurgery \& Psychiatry, 1992, 55, 181-184, doi: 10.1136/jnnp.55.3.181.

[24] M. M. Hoehn, M. D. Yahr, Parkinsonism: onset, progression, and mortality, Neurology, 1967, 17, 427, doi: 10.1212/wnl.17.5.427.

[25] P. G. Cf. Sm.-M, Movement Disorders, 2008, 1, 1-33, doi: 10.1002/mds.27121.

[26] G. Rizzo, M. Copetti, S. Arcuti, D. Martino, A. Fontana, G. Logroscino, Neurology, 2016, 86, 566-576, doi: 10.1212/wnl.0000000000002350.

[27] W. Tao, T. Liu, R. Zheng, H. Feng, Sensors, 2012, 12, $2255-$ 2283, doi: 10.3390/s120202255.

[28] W. Maetzler, J. Domingos, K. Srulijes, J. J. Ferreira, B. R. Bloem, Movement Disorders, 2013, 28, 1628-1637, doi: $10.1002 / \mathrm{mds} .25628$.

[29] A. Muro-de-la-Herran, B. Garcia-Zapirain, A. MendezZorrilla, Sensors, 2014, 14, 3362-3394, doi: 10.3390/s140203362.

[30] N. Kour, Sunanda, S. Arora, IEEE Access, 2019, 7, 156620 156645, doi: 10.1109/ACCESS.2019.2949744.

[31] C.-W. Cho, W.-H. Chao, S.-H. Lin, Y.-Y. Chen, Expert Systems with Applications, 2009, 36, 7033-7039, doi: 10.1016/j.eswa.2008.08.076.

[32] J. P. Singh, S. Jain, S. Arora, U. P. Singh, IEEE Access, 2018 , 6, 70497-70527, doi: 10.1109/access.2018.2879896.

[33] L. M. Quintero, IEEE Colombian conference on communications and computing (COLCOM), 2021, doi: 10.1109/colcom52710.2021.

[34] C. Tucker, Y. Han, H. Black Nembhard, W.-C. Lee, M. Lewis, N. Sterling, X. Huang, IIE Transactions on Healthcare Systems Engineering, 2015, 5, 238-254, doi: 


\section{$10.1080 / 19488300.2015 .1095256$}

[35] S. Aich, P. Mohan Pradhan, J. Park, H. Cheol Kim, International Journal of Engineering \& Technology, 2018, 7, 153, doi: 10.14419/ijet.v7i3.29.18547.

[36] M. Pistacchi, M. Gioulis, F. Sanson, E. de Giovannini, G. Filippi, F. Rossetto, S. Z. Marsala, Functional Neurolorogy, 2017, 32, 28-34, doi: 10.11138/fneur/2017.32.1.028.

[37] Y. P. Raykov, L. J. W. Evers, R. Badawy, B. R. Bloem, T. M. Heskes, M. J. Meinders, K. Claes, M. A. Little, IEEE Journal of Biomedical and Health Informatics, 2021, 25, 2293-2304, doi: 10.1109/jbhi.2020.303785.

[38] N. Chia Bejarano, E. Ambrosini, A. Pedrocchi, G. Ferrigno, M. Monticone, S. Ferrante, IEEE Transactions on Neural Systems and Rehabilitation Engineering, 2015, 23, 413-422, doi: 10.1109/tnsre.2014.2337914.

[39] Y. C. Han, K. I. Wong, I. Murray, IEEE Sensors Journal, 2019, 19, 3439-3448, doi: 10.1109/JSEN.2019.2894143.

[40] F. Parisi, G. Ferrari, M. Giuberti, L. Contin, V. Cimolin, C. Azzaro, G. Albani, A. Mauro, IEEE Journal of Biomedical and Health Informatics, 2015, 19, 1777-1793, doi: 10.1109/jbhi.2015.2472640.

[41] A. Salarian, H. Russmann, F. J. G. Vingerhoets, C. Dehollain, Y. Blanc, P. R. Burkhard, K. Aminian, IEEE Transactions on Biomedical Engineering, 2004, 51, 1434-1443, doi: 10.1109/tbme.2004.827933.

[42] M. Song, J. Kim, IEEE Transactions on Biomedical Engineering, 2018, 65, 885-893, 10.1109/TBME.2017.2724543.

[43] I. Carpinella, E. Gervasoni, D. Anastasi, T. Lencioni, D. Cattaneo, M. Ferrarin, IEEE Transactions on Neural Systems and Rehabilitation Engineering, 2018, 26, 2324-2332, doi: 10.1109/tnsre.2018.2881324.

[44] J. C. Perez-Ibarra, A. A. G. Siqueira, H. I. Krebs, IEEE Sensors Journal, 2020, 20, 14984-14993, doi: 10.1109/jsen.2020.3011627.

[45] J. C. Perez-Ibarra, A. A. G. Siqueira, H. I. Krebs, IEEE Transactions on Neural Systems and Rehabilitation Engineering, 2020, 28, 2933-2943, doi: 10.1109/tnsre.2020.3039999.

[46] E. Sejdic, K. A. Lowry, J. Bellanca, S. Perera, M. S. Redfern, J. S. Brach, IEEE Journal of Translational Engineering in Health and Medicine, 2016, 4, 1-11, doi: 10.1109/jtehm.2015.2504961. [47] S. R. Hundza, W. R. Hook, C. R. Harris, S. V. Mahajan, P. A. Leslie, C. A. Spani, L. G. Spalteholz, B. J. Birch, D. T. Commandeur, N. J. Livingston, IEEE Transactions on Neural Systems and Rehabilitation Engineering, 2014, 22, 127-137, doi: 10.1109/TNSRE.2013.2282080.

[48] Keloth, Viswanathan, Jelfs, Arjunan, Raghav, Kumar, Biosensors, 2019, 9, 59, doi: 10.3390/bios9020059.

[49] A. Vijayan, S. Janmasree, C. Keerthana, L. B. Syla, 2018 International CET Conference on Control, Communication, and Computing (IC4), 2018, 361-365, doi: 10.1109/cetic4.2018.8531032.

[50] M. Demonceau, A.-F. Donneau, J.-L. Croisier, E. Skawiniak, M. Boutaayamou, D. Maquet, G. Garraux, IEEE Journal of Biomedical and Health Informatics, 2015, 19, 1803-1808, doi: 10.1109/jbhi.2015.2469540.

[51] M. Yoneyama, H. Mitoma, N. Sanjo, M. Higuma, H. Terashi, T. Yokota, IEEE Transactions on Neural Systems and Rehabilitation Engineering, 2016, 24, 817-826, doi: 10.1109/tnsre.2015.2477856.

[52] L. Wang, Y. Sun, Q. Li, T. Liu, J. Yi, IEEE Robotics and Automation Letters, 2020, 5, 1970-1976, doi: 10.1109/1ra.2020.2970656

[53] A. R. Anwary, H. Yu, M. Vassallo, IEEE Sensors Journal, 2018, 18, 2555-2567, doi: 10.1109/jsen.2017.2786587.

[54] B. Mariani, M. C. Jiménez, F. J. G. Vingerhoets, K. Aminian, IEEE Transactions on Biomedical Engineering, 2013, 60, 155158, doi: 10.1109/tbme.2012.2227317.

[55] H.-C. Chang, Y.-L. Hsu, S.-C. Yang, J.-C. Lin, Z.-H. Wu, IEEE Access, 2016, 4, 8442-8453, doi: 10.1109/access.2016.2633304.

[56] M. I. Mohamed Refai, B.-J F. van Beijnum, J. H. Buurke, P. H. Veltink, IEEE Transactions on Neural Systems and Rehabilitation Engineering, 2019, 27, 218-227, doi: 10.1109/tnsre.2018.2885309.

[57] L. Rocchi, L. Palmerini, A. Weiss, T. Herman, J. M. Hausdorff, IEEE Transactions on Neural Systems and Rehabilitation Engineering, 2014, 22, 1064-1071, doi: 10.1109/tnsre.2013.2292496.

[58] M. Yoneyama, Y. Kurihara, K. Watanabe, H. Mitoma, IEEE Transactions on Neural Systems and Rehabilitation Engineering, 2013, 21, 999-1005, doi: 10.1109/tnsre.2013.2268251.

[59] M. Yoneyama, Y. Kurihara, K. Watanabe, H. Mitoma, IEEE Transactions on Neural Systems and Rehabilitation Engineering, 2014, 22, 613-622, doi: 10.1109/tnsre.2013.2260561.

[60] D. Jarchi, J. Pope, T. K. M. Lee, L. Tamjidi, A. Mirzaei, S. Sanei, IEEE Reviews in Biomedical Engineering, 2018, 11, 177 194, doi: 10.1109/rbme.2018.2807182.

[61] E. Sejdic, K. A. Lowry, J. Bellanca, M. S. Redfern, J. S. Brach, IEEE Transactions on Neural Systems and Rehabilitation Engineering, 2014, 22, 603-612, doi: 10.1109/tnsre.2013.2265887.

[62] M. Ullrich, S. Member, K. Arne, J. Hannink, S. D. Din, H. Gaßner, F. Marxreiter, J. Klucken, B. M. Eskofier, S. Member, F. Kluge, IEEE transactions on neural systems and rehabilitation engineering: a publication of the IEEE Engineering in Medicine and Biology Society, 2020, 24, 1869-1878, doi: 10.1109/TNSRE.2021.3119390.

[63] S. del Din, A. Godfrey, L. Rochester, IEEE Journal of Biomedical and Health Informatics, 2016, 20, 838-847, doi: 10.1109/jbhi.2015.2419317.

[64] J. A. Ramirez-Bautista, J. A. Huerta-Ruelas, S. L. ChaparroCárdenas, A. Hernández-Zavala, IEEE Reviews in Biomedical Engineering, 2017, 10, 299-309, doi: 10.1109/RBME.2017.2747402.

[65] G. Li, T. Liu, J. Yi, IEEE Sensors Journal, 2018, 18, 42344241, doi: 10.1109/jsen.2018.2814994.

[66] M. D. Djuric-Jovicic, N. S. Jovičić, S. M. Radovanović, I. D. Stankovic, M. B. Popovic, V. S. Kostic, IEEE Transactions on Neural Systems and Rehabilitation Engineering, 2013, 22, 685- 
694, doi: 10.1109/TNSRE.2013.2287241.

[67] V. Agostini, G. Balestra, M. Knaflitz, IEEE Transactions on Neural Systems and Rehabilitation Engineering, 2014, 22, 946952, doi: 10.1109/tnsre.2013.2291907.

[68] K. N. Winfree, I. Pretzer-Aboff, S. K. Agrawal, IEEE Transactions on Neural Systems and Rehabilitation Engineering, 2015, 23, 1012-1019, doi: 10.1109/tnsre.2014.2382641.

[69] S. Bamberg, A. Y. Benbasat, D. M. Scarborough, D. E. Krebs, J. A. Paradiso, IEEE Transactions on Information Technology in Biomedicine, 2008, 12, 413-423, doi: 10.1109/titb.2007.899493. [70] M. E. Morris, R. Iansek, Human Movement Science, 1996, 15, 649-669, doi: 10.1016/0167-9457(96)00020-6.

[71] R. Mishra, K. Chaudhary, I. Mishra, Current Pharmaceutical Biotechnology, 2022, doi: 10.2174/1389201023666220929145220.

[72] M. Son, C. Youm, S. Cheon, J. Kim, M. Lee, Y. Kim, J. Kim, H. Sung, Aging Clinical and Experimental Research, 2017, 29, 1191-1199, doi: 10.1007/s40520-016-0719-y.

[73] M. E. Morris, R. Iansek, T. A. Matyas, J. J. Summers, Brain, 1994, 117, 1169-1181, doi: 10.1093/brain/117.5.1169.

[74] J. M. Hausdorff, Journal of Neuro Engineering and Rehabilitation, 2005, 2, 1-7, doi: 10.1186/1743-0003-2-19.

[75] J. Richards, D. Levine, M. W. Whittle, Whittle's Gait Analysis-E-Book, Elsevier Health Sciences, 2022.

[76] R. Bouça-Machado, C. Jalles, D. Guerreiro, F. Pona-Ferreira, D. Branco, T. Guerreiro, R. Matias, J. J. Ferreira, Journal of Parkinson's Disease, 2020, 10, 843-853, doi: 10.3233/jpd201969.

[77] M. Morris, R. Iansek, T. Matyas, J. Summers, Movement Disorders, 1998, 13, 61-69, doi: 10.1002/mds.870130115.

[78] R. W. Bohannon, Age and Ageing, 1997, 26, 15-19, doi: 10.1093/ageing/26.1.15.

[79] R. B. Dale, Clinical Gait Assessment, Physical Rehabilitation of the Injured Athlete, 2012, 464-479, doi: 10.1016/B978-1-4377-2411-0.00021-6.

[80] S. Lahmiri, IEEE Transactions on Instrumentation and Measurement, 2019, $\quad \mathbf{6 8}, \quad 2545-2551, \quad$ doi: 10.1109/TIM.2018.2866316.

[81] A. L. Goldberger, L. A. N. Amaral, L. Glass, J. M. Hausdorff, P. C. Ivanov, R. G. Mark, J. E. Mietus, G. B. Moody, C.-K. Peng, H. E. Stanley, PhysioBank, PhysioToolkit, PhysioNet, Circulation, 2000, 101: doi: 10.1161/01.cir.101.23.e215.

[82] S. Frenkel-Toledo, N. Giladi, C. Peretz, T. Herman, L. Gruendlinger, J. M. Hausdorff, Movement Disorders, 2005, 20, 1109-1114, doi: 10.1002/mds.20507.

[83] J. M. Hausdorff, J. Lowenthal, T. Herman, L. Gruendlinger, C. Peretz, N. Giladi, European Journal of Neuroscience, 2007, 26, 2369-2375, doi: 10.1111/j.1460-9568.2007.05810.x.

[84] G. Yogev, N. Giladi, C. Peretz, S. Springer, E. S. Simon, J. M. Hausdorff, European Journal of Neuroscience, 2005, 22, 1248-1256, doi: 10.1111/j.1460-9568.2005.04298.x.

[85] A. Weiss, T. Herman, M. Plotnik, M. Brozgol, I. Maidan, N. Giladi, T. Gurevich, J. M. Hausdorff, Medical Engineering \& Physics, 2010, 32, 119-125, doi: 10.1016/j.medengphy.2009.10.015.
[86] A. Mirelman, T. Gurevich, N. Giladi, A. Bar-Shira, A. OrrUrtreger, J. M. Hausdorff, Annals of Neurology, 2011, 69, 193197, doi: 10.1002/ana.22165.

[87] A. Mirelman, T. Heman, K. Yasinovsky, A. Thaler, T. Gurevich, K. Marder, S. Bressman, A. Bar-Shira, A. Orr-Urtreger, N. Giladi, J. M. Hausdorff, Movement Disorders, 2013, 28, 1683 1690, doi: 10.1002/mds.25587.

[88] A. Mirelman, H. Bernad-Elazari, A. Thaler, E. Giladi-Yacobi, T. Gurevich, M. Gana-Weisz, R. Saunders-Pullman, D. Raymond, N. Doan, S. B. Bressman, K. S. Marder, R. N. Alcalay, A. K. Rao, D. Berg, K. Brockmann, J. Aasly, B. J. Waro, E. Tolosa, D. Vilas, C. Pont-Sunyer, A. Orr-Urtreger, J. M. Hausdorff, N. Giladi, Movement Disorders, 2016, 31, 1527-1534, doi: $10.1002 / \mathrm{mds} .2672$.

[89] N. Khoury, F. Attal, Y. Amirat, L. Oukhellou, S. Mohammed, Sensors, 2019, 19, 242, doi: 10.3390/s19020242.

[90] A. Khorasani, M. R. Daliri, Journal of Medical Systems, 2014, 38, 1-6, doi:10.1007/s10916-014-0147-5.

[91] R. Alkhatib, M. O. Diab, C. Corbier, M. E. Badaoui, IEEE Sensors Letters, 2020, 4, 1-4, doi: 10.1109/1sens.2020.2994938.

[92] A. Dzikri, D. E. Kurniawan, 2018 International Conference on Applied Engineering (ICAE), 2018, 1-5, doi: 10.1109/INCAE.2018.8579400.

[93] M. R. Daliri, Biomedical Signal Processing and Control, 2013, 8, 66-70, doi: 10.1016/j.bspc.2012.04.007.

[94] Y. Wu, P. Chen, X. Luo, M. Wu, L. Liao, S. Yang, R. M. Rangayyan, Biomedical Signal Processing and Control, 2017, 31, 265-271, doi: 10.1016/j.bspc.2016.08.022.

[95] J. Celis, R. Llanos, S. Castro, S. Sepulveda, B. Medina, D. Guevara, L. Camargo, J. Gómez, International Conference on Automation and Computational engineering (ICACE), 2018, doi: 10.1109/icace44052.2018.

[96] D. Joshi, A. Khajuria, P. Joshi, Computer Methods and Programs in Biomedicine, 2017, 145, 135-145, doi: 10.1016/j.cmpb.2017.04.007.

[97] H. S. Jeon, J. Han, W. J. Yi, B. Jeon, K. S. Park, Proceedings of the 30th Annual International Conference of the IEEE Engineering in Medicine and Biology Society, 2008, 4672-4675. [98] N. Alam, A. Garg, T. Tabassum, K. Munia, R. Fazel, K. Tavakolian, PloS One, 2017, 12, 1-13, doi: 10.1371/journal.pone.0175951.

[99] E. Abdulhay, N. Arunkumar, K. Narasimhan, E. Vellaiappan, V. Venkatraman, Future Generation Computer Systems, 2018, 83, 366-373, doi: 10.1016/j.future.2018.02.009.

[100] J. C. Vasquez-Correa, T. Arias-Vergara, J. R. OrozcoArroyave, B. Eskofier, J. Klucken, E. Noth, IEEE Journal of Biomedical and Health Informatics, 2019, 23, 1618-1630, doi: 10.1109/jbhi.2018.2866873.

[101] T. Nooritawati, M. Hazfiza, Journal of Applied Science, 2012, 12, 180-185, doi:10.3923/jas.2012.

[102] I. El Maachi, G. A. Bilodeau, W. Bouachir, Expert Systems with Applications, 2020, 143, 1-27, doi: 10.1016/j.eswa.2019.113075.

[103] Y. Xia, Z. Yao, Q. Ye, N. Cheng, IEEE Transactions on Neural Systems and Rehabilitation Engineering, 2020, 28, 42-51, 
doi: 10.1109/tnsre.2019.2946194.

[104] T. O'Shea, K. Karra, T. Clancy, IEEE international symposium on signal processing and information technology, 2016, 12-14, doi: 10.1109/isspit39456.2016.

[105] W. Zeng, F. Liu, Q. Wang, Y. Wang, L. Ma, Y. Zhang, Neuroscience Letters, 2016, 633, 268-278, doi: 10.1016/j.neulet.2016.09.043.

[106] A. K. Bhoi, International Journal Bioautomation, 2017, 21, 19-30.

[107] Y. Yan, O. M. Omisore, Y.-C. Xue, H.-H. Li, Q.-H. Liu, Z.D. Nie, J. Fan, L. Wang, IEEE Access, 2020, 8, 96363-96377, doi: 10.1109/access.2020.2996667.

[108] M. R. Daliri, Measurement, 2012, 45, 1729-1734, doi: 10.1016/j.measurement.2012.04.013.

[109] D. Zhang, K. Hwa, 2021 8th international conference on biomedical and bioinformatics engineering, 2021, doi: $10.1145 / 3502871$.

[110] R. Z. U. Rehman, C. Buckley, M. E. Mico-Amigo, C. Kirk, M. Dunne-Willows, C. Mazza, J. Q. Shi, L. Alcock, L. Rochester, S. del Din, IEEE Open Journal of Engineering in Medicine and Biology, 2020, 1, 65-73, doi: 10.1109/ojemb.2020.296629.

[111] R. Z. U. Rehman, S. Del Din, Y. Guan, A. J. Yarnall, J. Q. Shi, L. Rochester, Scientific Reports, 2019, 9, 17269, doi: 10.1038/s41598-019-53656-7.

[112] R. Z. U. Rehman, S. del Din, J. Q. Shi, B. Galna, S. Lord, A. J. Yarnall, Y. Guan, L. Rochester, Sensors, 2019, 19, 5363, doi: $10.3390 / \mathrm{s} 19245363$.

[113] F. Wahid, R. K. Begg, C. J. Hass, S. Halgamuge, D. C. Ackland, IEEE Journal of Biomedical and Health Informatics, 2015, 19, 1794-1802, doi: 10.1109/jbhi.2015.2450232.

[114] T. D. Pham, H. Yan, IEEE Transactions on Biomedical Engineering, 2018, 65, 1820-1827, doi: 10.1109/TBME.2017.2779884.

[115] F. Parisi, G. Ferrari, M. Giuberti, L. Contin, V. Cimolin, C. Azzaro, G. Albani, A. Mauro, IEEE Transactions on Affective Computing, 2016, 7, 258-271, doi: 10.1109/taffc.2016.2549533. [116] E. Balaji, D. Brindha, V. K. Elumalai, K. Umesh, Medical Engineering \& Physics, 2021, 91, 54-64, doi: 10.1016/j.medengphy.2021.03.005.

[117] E. Balaji, D. Brindha, V. K. Elumalai, R. Vikrama, Applied Soft Computing, 2021, 108, 107463, doi: 10.1016/j.asoc.2021.107463.

[118] A. S. Alharthi, A. J. Casson, K. B. Ozanyan, IEEE Sensors Journal, 2021, 21, 1838-1848, doi: 10.1109/jsen.2020.3018262. [119] A. Zhao, L. Qi, J. Li, J. Dong, H. Yu, Neurocomputing, 2018, 315, 1-8, doi: 10.1016/j.neucom.2018.03.032.

[120] T. Așuroğlu, K. Açıcı, Ç. Berke Erdaş, M. Kılınç Toprak, H. Erdem, H. Oğul, Biocybernetics and Biomedical Engineering, 2018, 38, 760-772, doi: 10.1016/j.bbe.2018.06.002.

[121] C. Caramia, D. Torricelli, M. Schmid, A. Munoz-Gonzalez, J. Gonzalez-Vargas, F. Grandas, J. L. Pons, IEEE Journal of Biomedical and Health Informatics, 2018, 22, 1765-1774, doi: 10.1109/jbhi.2018.2865218.

[122] N. Naghavi, A. Miller, E. Wade, Sensors, 2019, 19, 3898, doi: $10.3390 / \mathrm{s} 19183898$.
[123] Y. Zhang, W. Yan, Y. Yao, J. B. Ahmed, Y. Tan, D. Gu, IEEE Transactions on Neural Systems and Rehabilitation Engineering, 2020, 28, 591-600, doi: 10.1109/tnsre.2020.2969649.

[124] F. Demrozi, R. Bacchin, S. Tamburin, M. Cristani, G. Pravadelli, IEEE Journal of Biomedical and Health Informatics, 2020, 24, 2444-2451, doi: 10.1109/jbhi.2019.2952618.

[125] J. Prince, F. Andreotti, M. de Vos, IEEE Transactions on Biomedical Engineering, 2019, 66, 1402-1411, doi: 10.1109/tbme.2018.2873252.

[126] P. Ren, E. Karahan, C. Chen, R. Luo, Y. Geng, J. F. Bosch Bayard, M. L. Bringas, D. Yao, K. M. Kendrick, P. A. ValdesSosa, IEEE Transactions on Neural Systems and Rehabilitation Engineering, 2017, 25, 1257-1267, doi: $10.1109 /$ tnsre.2016.2622285.

[127] A. Turner, S. Hayes, IEEE Transactions on Biomedical Engineering, 2019, 66, 3136-3145, doi: 10.1109/TBME.2019.2900863.

[128] J. G. Nutt, B. R. Bloem, N. Giladi, M. Hallett, F. B. Horak, A. Nieuwboer, The Lancet Neurology, 2011, 10, 734-744, doi: 10.1016/s1474-4422(11)70143-0.

[129] M. Bachlin, M. Plotnik, D. Roggen, I. Maidan, J. M. Hausdorff, N. Giladi, G. Troster, IEEE Transactions on Information Technology in Biomedicine, 2010, 14, 436-446, doi: 10.1109/titb.2009.2036165.

[130] Y. Guo, L. Wang, Y. Li, L. Guo, F. Meng, IEEE Transactions on Neural Systems and Rehabilitation Engineering, 2019, 27, 2077-2086, doi: 10.1109/tnsre.2019.2938301.

[131] S. Mazilu, A. Calatroni, E. Gazit, A. Mirelman, J. M. Hausdorff, G. Troster, IEEE Journal of Biomedical and Health Informatics, 2015, 19, 1843-1854, doi: 10.1109/jbhi.2015.2465134.

[132] N. Naghavi, E. Wade, IEEE Transactions on Neural Systems and Rehabilitation Engineering, 2019, 27, 947-955, doi: 10.1109/TNSRE.2019.2910165.

[133] T. T. Pham, S. T. Moore, S. J. G. Lewis, D. N. Nguyen, E. Dutkiewicz, A. J. Fuglevand, A. L. McEwan, P. H. W. Leong, IEEE Transactions on Biomedical Engineering, 2017, 64, 27192728, doi: 10.1109/TBME.2017.2665438.

[134] J. McDonnell, J. Dripps, P. Grant, Proceedings of the annual international conference of the IEEE engineering in medicine and biology society, 1989, doi: 10.1109/iembs.2003.1279435.

[135] D. Ahn, H. Chung, H.-W. Lee, K. Kang, P.-W. Ko, N. S. Kim, T. Park, IEEE Transactions on Biomedical Engineering, 2017, 64, 2394-2402, doi: 10.1109/tbme.2017.2655344.

[136] V. Mikos, C.-H. Heng, A. Tay, S.-C. Yen, N. S. Y. Chia, K. M. L. Koh, D. M. L. Tan, W. L. Au, IEEE Transactions on Biomedical Circuits and Systems, 2019, 13, 503-515, doi: 10.1109/tbcas.2019.2914253.

Publisher's Note: Engineered Science Publisher remains neutral with regard to jurisdictional claims in published maps and institutional affiliations. 